\title{
Situación y horizontes de la producción científica y la innovación tecnológica en Colombia. Manifiesto.
}

Los firmantes nos manifestamos a favor de:

I. El cultivo de la razón, fuente de las ciencias, las artes y los valores universales.

II. La formación sólida de las personas en competencias lógicas, matemáticas, científicas y de emprendimiento en todas las etapas y modalidades de enseñanza.

III. El incremento cuantitativo y cualitativo de la producción científica mediante la generación de condiciones especiales para su desarrollo a nivel individual, colectivo y organizacional.

IV. La construcción de vasos comunicantes entre los campos científico y de innovación tecnológica, salvaguardando su autonomía relativa.

V. La construcción y desarrollo de líneas de innovación tecnológica que permitan la producción de bienes o servicios de alto valor agregado, comercializables en el mercado mundial y con altos rendimientos.

VI. El fomento integral, continuo y paciente, por parte del Estado, a los procesos de producción científica y los avances tecnológicos, y al surgimiento de economías innovadoras ajustadas a los Objetivos de Desarrollo Sostenible.

VII. La sujeción creciente de las decisiones del Estado y que comprometan intereses públicos a la recolección de datos, análisis de información y producción de conocimientos, orientados por principios y metodologías científicas.

VIII. La divulgación de la ciencia y la innovación tecnológica que tenga como objetivo el aumento de su comprensión y aquiescencia por parte del Estado y de los ciudadanos.

IX. La respuesta integral, continua y urgente del Estado y la ciudadanía, orientada por el conocimiento y las soluciones innovadoras, a la amenaza del cambio climático.

X. La acción política ciudadana, programática, a favor de la razón, la ciencia y las economías innovadoras. 